\title{
EFEKTIFITAS PEMBELAJARAN MATEMATIKA DENGAN STRATEGI INKUIRI YANG DILENGKAPI PEMBAHASAN TUGAS TERSTRUKTUR DALAM MENINGKATKAN HASIL BELAJAR MATEMATIKA PADA SISWA KELAS VIII SMP NEGERI 2 BAUBAU
}

\author{
${ }^{1)}$ Suwarni La Usa dan 2) Dian Lestari \\ $\left({ }^{1)} \& 2\right)$ Dosen Program Studi Pendidikan Matematika, Universitas Dayanu Ikhsanuddin Baubau) \\ E-mail: An_nyie03@yahoo.co.id; dian7lestari@gmail.com
}

\begin{abstract}
ABSTRAK
Masalah dalam penelitian ini "Apakah hasil belajar matematika siswa kelas VIII SMP Negeri 2 Baubau yang diajar dengan metode inquire lebih baik dibandingkan yang diajar dengan ekspositori? Tujuan dari penelitian ini adalah untuk mengetahui metode pembelajaran yang lebih efektif dalam meningkatkan hasil belajar matematika siswa antara metode inquire dan metode ekspositori. Populasi dalam penelitian ini adalah seluruh siswa kelas VIII SMP Negeri 2 Baubau Tahun Pelajaran 2017/2018, adapun tehnik pengambilan sampel dengan tehnik one stage cluster random dengan sampel sebanyak 2 kelas yang terdiri dari kelas kontrol dan kelas eksperimen. Berdasarkan hasil output uji normalitas dengan menggunakan uji Kolmogorov-Smirnov, untuk kelas eksperimen nilai KSZ sebesar 0,930 dan Asym.sig. sebesar 0,352 dan kelas kontrol nilai KSZ 1,157 dan Asymp.sig. sebesar 0,137. Karena nilai signifikansi kedua kelas lebih besar dari $1 / 2 \alpha(0,025)$ maka dapat disimpulkan bahwa data hasil belajar matematika kelas eksperimen dan kelas kontrol berdistribusi normal. Sedangkan analisis uji $\mathrm{f}$ nilai progres dengan menggunakan program IBM SPSS 21 diperoleh nilai $\mathrm{F}$ adalah 0,061 signifikan pada 0,807 lebih besar dari $1 / 2 \alpha(0,025)$, sehingga disimpulkan bahwa kedua kelas berasal dari varians yang homogen. Hasil uji-t diperoleh nilai thitung 3,336 sig.(2-tailed) pada 0,002 lebih kecil dari $1 / 2 \alpha(0,025)$ sehingga disimpulkan $\mathrm{H}_{0}$ ditolak dan $\mathrm{H}_{1}$ diterima. Hal ini berarti model pembelajaran inkuiri yang dilengkapi pemberian tugas terstruktur lebih efektif dibandingkan dengan model pembelajaran ekspositori.
\end{abstract}

Kata Kunci: Pembelajaran, inkuiri, efektif

\section{ABSTRACT}

Problems in this study "Are the mathematics learning outcomes of class VIII students of SMP Negeri 2 Baubau taught by the Inquire method better than those taught by expository.? The purpose of this study was to find out more effective learning methods in improving students' mathematics learning outcomes between inquire methods and expository methods. The population in this study were all students of class V SDN 2 Bataraguru, while the sampling technique with One stage cluster random technique with a sample of 2 classes consisting of the control class and the experimental class. Based on the output of the normality test using the Kolmogorov-smirnov test, for the experimental class the KSZ values were 0.930 and Asym. Sig. amounting to 0.352 and the KSZ 1.157 and Asymp.sig value control classes. amounting to 0.137. Because the significance value of the two classes is greater than $1 / 2 \alpha(0.025)$, it can be concluded that the data on the mathematics learning outcomes of the experimental class and the control class are normally distributed. While the analysis of the f test progress value using the IBM SPSS 21 program obtained $F$ value is 0.061 significant at 0.807 greater than $1 / 2 \alpha$ (0.025), so it is concluded that the two classes are based on homogeneous variance. The t-test results obtained values 3.336 sig. (2-tailed) at 0.002 smaller than $1 / 2 \alpha(0.025)$ so that it was concluded that $\mathrm{HO}$ was rejected and $\mathrm{H} 1$ was accepted. This means that the inquiry learning 
model which is equipped with structured assignments is more effective than the expository learning model.

Keywords: Learning, Inquiri, effective

\section{PENDAHULUAN}

Interaksi belajar mengajar yang baik adalah guru sebagai pengajar tidak mendominasi kegiatan, tetapi membantu menciptakan kondisi yang kondusif serta memberikan motivasi dan bimbingan agar siswa dapat mengembangkan potensi dan kreativitasnya melalui kegiatan belajar. Oleh karena itu dalam pembelajaran, faktor keaktifan siswa sebagai subyek belajar sangat menentukan. Siswa yang baik memiliki karakter bersemangat tinggi dalam memecahkan suatu masalah yang dihadapinya atau suatu masalah dimohonkan kepadanya untuk dipecahkan, tidak harus ada pada siswa yang cerdas. Namun, bagi siswa yang berkemampuan rata-rata sedang atau kurangpun dapat dilatih untuk memiliki karakter yang mampu menyelesaikan masalah.

Karena belajar matematika, yang dipentingkan adalah bagaimana membentuk pengertian pada anak. Ini berarti bahwa belajar matematika penekanannya adalah pada proses anak belajar, sedangkan guru sebagai fasilitator. Dalam pembelajaran matematika, difokuskan lebih pada penekanan knowing how, yaitu belajar di pandang sebagai orang yang aktif dalam mengkonstruksi ilmu pengetahuan dengan cara berinteraksi dengan lingkungannya.

Kecakapan hidup seseorang tidak terjadi dengan sendirinya tetapi melalui suatu proses yang terus berlanjut. Keberlanjutan perkembangan proses kecakapan hidup atau keterampilan hidup seseorang selama proses pembelajaran sebenarnya dapat diamati. Hal ini juga berlaku bagi siswa, dimana perkembangan keterampilan proses seorang siswa selama proses pembelajaran dapat diikuti atau diamati.

Keterampilan proses merupakan salah satu aspek yang sangat penting dalam suatu proses pembelajaran matematika. Mengajar dengan keterampilan proses berarti memberi kesempatan siswa untuk bekerja dengan ilmu pengetahuan, tidak sekedar menceritakan atau mendengarkan cerita tentang ilmu pengetahuan, karena sebenarnya melalui pembelajaran matematika tidak semata-mata hanya menanamkan pengetahuan saja. Tetapi sangat mungkin diterapkan pembentukan sikap positif, keterampilan cermat, dan kritis.

Siswa SD merupakan peralihan dari tahap operasional konkret menuju tahap operasional formal. Pelajaran matematika di sekolah merupakan pelajaran yang bersifat abstrak, sehingga diperlukan strategi pembelajaran yang tepat untuk mengajarkan matematika agar siswa lebih mudah memahami konsep yang terkandung dalam setiap materi yang di pelajari. Karena sampai saat ini masih banyak kesulitan yang dihadapi siswa dalam belajar matematika. Hal ini disebabkan karena banyaknya faktor-faktor tertentu, seperti anggapan bahwa pembelajaran sulit dan kurang diperhatikannya keterampilan proses selama pembelajaran matematika berlangsung. Sehingga hal tersebut akhirnya berpengaruh terhadap hasil belajar matematika.

Islam sesungguhnya telah memberikan arahan tentang beberapa tahapan atau fase dari setiap strategi yang 
tepat dalam setiap proses pembelajaran. AlQur'an menjelaskan dalam surat AlZalzalah ayat 7-8, yang artinya sebagai berikut "Barang siapa yang mengerjakan kebaikan seberat dzarrahpun, niscaya dia akan melihat (balasan)nya. Dan barang siapa yang mengerjakan kejahatan seberat dzarrahpun niscaya dia akan melihat (balasan) nyapula".

Ayat Al-Qur'an ini memberikan gambaran bahwa dalam setiap pembelajaran, hendaknya guru memberikan satu bentuk motivasi yang berkaitan langsung dengan materi yang akan disampaikan pada proses, atau motivasi yang pada akhirnya dapat mendorong setiap siswa untuk belajar lebih giat dalam mengikuti dan mempelajari semua materi pada setiap pembelajaran.

Berdasarkan penuturan salah satu guru kelas V di SMP Negeri 2 Baubau, bahwa masih banyak siswa yang kurang memahami materi pelajaran matematika yang diajarkan. Hal ini salah satu penyebabnya adalah penggunaan stretegi pembelajaran di kelas tersebut masih kurang efektif dengan menggunakan metode pembelajaran ekspositori.

Penggunaan metode ekspositori merupakan metode pembelajaran yang mengarah kepada tersampaikannya isi pelajaran kepada siswa secara langsung. dampak penggunaan metode ini siswa tidak perlu mencari dan menemukan sendiri fakta-fakta, konsep dan prinsip karena sudah disajikan secara jelas oleh guru. Kegiatan pembelajaran dengan menggunakan metode ekspositori cenderung berpusat kepada guru. Namun penggunaan metode tersebut sangat efektif apabila meteri pelajaran yang harus dikuasai oleh siswa cukup luas, sementara waktu yang digunakan cukup terbatas.

Untuk mengatasi hal tesebut diperlukan suatu strategi pembelajaran yang tepat, menarik dan dapat bertanya meskipun tidak pada guru secara langsung, mengemukakan pendapat, serta dapat meningkatkan keterampilan proses siswa. Salah satu solusinya adalah dengan menggunakan strategi pembelajaran inkuiri.

Strategi pembelajaran inkuiri merupakan strategi pembelajaran yang menekankan kepada perkembangan aspek kognitif, afektif dan psikomotorik secara seimbang, sehingga pembelajaran melalui strategi ini dianggap lebih bermakna, selain itu juga dapat memberikan ruang kepada siswa untuk belajar sesuai dengan gaya belajar mereka. Hal tersebut akan sulit diimplementasikan oleh setiap guru karena pada strategi inkuiri ini kriteria keberhasilan belajar ditentukan oleh kemampuan siswa menguasai materi pelajaran, sehingga setiap guru harus benar-benar menguasai penggunaan startegi pembelajaran inkuiri dengan baik.

Berdasarkan uraian di atas, maka penulis tertarik mengangkat sebuah judul "Efektifitas Pembelajaran Matematika dengan Strategi Inkuiri yang Dilengkapi Pembahasan Tugas Terstruktur dalam Meningkatkan Hasil Belajar Matematika pada Siswa Kelas VIII SMP Negeri 2 Baubau".

\section{METODE PENELITIAN}

\section{Jenis penelitian}

Jenis penelitian ini adalah penelitian eksperimen dan bersifat kuantitatif. Penelitian ini telah dilaksanakan di SMP
Negeri 2 Baubau pada semester genap tahun ajaran 2017/2018. 


\section{Populasi dan Sampel}

Populasi dalam penelitian ini adalah seluruh siswa kelas VIII SMP Negeri 2 Baubau Tahun Pelajaran 2017/2018. Sampel dalam penelitian ini diambil dua kelas dengan kemampuan akademik yang cenderung homogen. Untuk kelas eksperimen yakni kelas VIII.3 diberi pembelajaran dengan menggunakan srategi inkuiri yang dilengkapi tugas terstruktur sedangkan, kelas kontrol yakni kelas VIII.1 diberi pembelajaran dengan menggunakan model pembelajaran ekspositori. Teknik pengambilan sampel dalam penelitian ini menggunakan one stage cluster random sampling. One stage cluster random sampling adalah pengambilan sampel secara random atau acak sesuai dengan kelas yang ada. Cara yang digunakan untuk menentukan sampel dengan teknik ini adalah dengan cara undian. Teknik one stage cluster random sampling digunakan dalam menentukan sampel penelitian atas dasar bahwa populasi dalam keadaan homogen.

\section{Desain Penelitian}

Bentuk designtrue experimental dalam penelitian ini adalah pretest - postest control group design.

\begin{tabular}{|c|c|c|c|}
\hline $\mathrm{E}$ & $\mathrm{O} 1$ & $\mathrm{X} 1$ & $\mathrm{O} 2$ \\
\hline $\mathrm{K}$ & $\mathrm{O} 3$ & $\mathrm{X} 2$ & $\mathrm{O} 4$ \\
\hline
\end{tabular}

Gambar 1. Pretest-Posttest control group design

Keterangan:

E : Kelompok eksperimen dan kontrol siswa SMP Negeri 2 Baubau.

$\mathrm{K}$ : Kelas kontrol menggunakan metode ekspositori.

O1 dan O3 : Hasil Belajar awal kedua kelompok dengan menggunakan Pre Test.
O2 : Hasil belajar setelah mengikuti pembelajaran dengan strategi pembelajaran inkuiri yang dilengkapi pembahasan tugas terstruktur.

O4: Hasil belajar menggunakan metode ekspositori.

X1: Treatment Kelompok atas sebagai kelompok eksperimen di beri treatment yaitu pembelajaran dengan menggunakan strategi pembelajaran inkuiri yang dilengkapi pembahasan tugas terstruktur.

X2 : Kelompok bawah yang merupakan kelompok kontrol diberikan pembelajaran dengan menggunakan strategi ekspositori

\section{Instrumen Penelitian}

Adapun instrumen yang digunakan dalam penelitian ini adalah: a) Lembar observasi; b) Tes. Lembar observasi pada penelitian ini digunakan untuk mengamati kegiatan siswa yang diharapkan muncul dalam pembelajaran matematika dengan strategi inkuiri yang dilengkapi pembahasan tugas terstruktur. Tes digunakan untuk memperoleh data tentang hasil belajar siswa pada materi peluang. Sebelum digunakan dalam penelitian terlebih dahulu divalidasi pada ahli. Soal terdiri dari 5 nomor soal essay dan masing-masing kelas diberikan soal yang sama.

\section{Teknik Pengumpulan Data}

Dalam melakukan peneliti menggunakan lembar observasi yang digunakan untuk mencatat semua gejalagejala yang muncul ketika pembelajaran berlangsung. Pengamatan dilakukan di dalam kelas ketika proses pembelajaran berlangsung. Tes akan diberikan kepada semua kelas sampel dengan soal yang sama. Namun, pelaksanaan tes akan diberikan sesuai dengan jadwal mata pelajaran matematika di kelas. Dalam penelitian ini, tes diberikan sebagai tes awal sebelum 
diberikan tindakan, dan pemberian tes akhir akan dilaksanakan setelah tindakan dengan pembelajaran inkuiri yang dilengkapi tugas terstruktur pada kelas ekperimen pembelajaran ekspositori pada kelas kontrol.

\section{Teknik Analisis Data}

Data yang dikumpulkan dalam penelitian ini dianalisis dengan, a) analisis Deskriptif; b) analisis Inferensial. Analisis deskriptif dalam penelitian ini digunakan untuk menganalisis frekuensi, presentase, median, modus, dan rata-rata untuk mendeskripsikan masing-masing variabel. Selanjutnya analisis inferensial terbagi lagi atas dua yaitu: 1) Uji Prasyarat, 2) Uji Kesamaan Dua Rata-rata. Uji prasyarat dalam analisis Inferensial terbagi lagi atas dua yaitu uji Normalitas dan uji Homogenitas. Sebelum melakukan uji hipotesis, terlebih dahulu dilakukan uji normalitas untuk mengetahui apakah data yang diteliti berasal dari populasi yang berdistribusi normal atau tidak. Untuk keperluan ini digunakan uji Kolmogorov Smirnov (Djwanto, 1997: 50). Adapun langkah langkah yang diperlukan dalam pengujian Kolmogrov Smirnov yaitu:

1) Data dari hasil pengamatan disusun mulai dari nilai pengamatan terkecil sampai nilai pengamatan terbesar.

2) Dari data pengamatan tersebut, kemudian disusun distribusi frekuensi komulatif relatif dan dinotasikan dengan $\mathrm{Fa}(\mathrm{y})$.

3) Menghitung nilai $Z$ dengan rumus $Z=\frac{y-\mu}{\sigma}$, dimana $\mu$ adalah rata rata dan oadalah standar deviasi.

4) Menghitung distribusi frekuensi kumulatif teoritis (berdasarkan kurva normal) dan dinotasikan dengan $\mathrm{Fe}(\mathrm{y})$.
5) Menghitung selisih antara $\mathrm{Fa}(\mathrm{y})$ dengan $\mathrm{Fe}(\mathrm{y})$.

6) Mengambil angka selisih maksimum dan dinotasikan $\mathrm{D}$.

$\mathrm{D}=$ maks $|F a(y)-F e(y)|$

7) Bandingkan nilai $D$ yang diperoleh dengan nilai $\frac{1,36}{\sqrt{n}}$ (tabel nilai D untuk uji Kolmogorov Smirnov).

Kriteria pengambilan keputusan adalah:

Ho diterima jika $\mathrm{D} \leq \mathrm{D} \alpha$

Ho ditolak jika $\mathrm{D} \geq \mathrm{D} \alpha$

Uji homogenitas dilakukan untuk mengetahui apakah kedua kelas mempunyai varians yang sama atau tidak.

Rumus yang digunakan:

$$
F_{\text {hitung }}=\frac{\text { varians terbesar }}{\text { varians terkecil }}
$$

Kriteria pengujian adalah:

Jika $F_{\text {hitung }}<\frac{1}{2} \alpha\left(v_{1} v_{2}\right)$ dengan $v_{1}=n_{1}-1$ (dk pembilang), dan $v_{2}=n_{2}-1 \quad(\mathrm{dk}$ penyebut) dan $=5 \%$ maka data bervarians homogen.

Selanjutnya dilakukan uji kesamaan dua rata-rata, karena kedua kelas berasal dari varians yang homogen, maka rumus yang digunakan adalah sebagai berikut:

$$
S^{2}=\frac{\left(n_{1}-1\right) S_{1}^{2}+\left(n_{2}+1\right) S_{2}^{2}}{n_{1}+n_{2}-2}
$$

dan

$$
t=\frac{y_{1}-y_{2}}{\sqrt[s]{\frac{1}{n_{1}}+\frac{1}{n_{2}}}}
$$

Kriteria pengujian adalah:

Jika $-t_{1}-1 / 2<t$ hitung $<t_{1}-1 / 2$ dengan $\mathrm{dk}=n_{1}+n_{2}-2$ dan $=5 \%$ maka rata-rata hasil belajar kelas eksperimen sama dengan kelas kontrol. 


\section{HASIL DAN PEMBAHASAN}

\section{Target dan Capaian Penelitian}

Adapun hasil capaian penelitian yang diperoleh hingga laporan kemajuan ini dibuat adalah sebagai berikut:

Tabel 1. Tahapan Pencapaian Penelitian

\begin{tabular}{|l|r|r|r|r|}
\hline \multicolumn{2}{|c|}{ Statistics } \\
\hline \multicolumn{1}{|c|}{$\begin{array}{c}\text { Pree Tes } \\
\text { Ekperimen }\end{array}$} & $\begin{array}{c}\text { Post Tes } \\
\text { Ekperimen }\end{array}$ & $\begin{array}{c}\text { Pree Tes } \\
\text { Kontrol }\end{array}$ & $\begin{array}{c}\text { Post Tes } \\
\text { Kontrol }\end{array}$ \\
\hline N $\quad 20$ & 20 & 20 & 20 \\
Mean & 0 & 0 & 0 & 0 \\
Std. Error of Mean & 54,0000 & 72,0000 & 55,5000 & 67,2500 \\
Median & 2,33959 & 2,21834 & 2,11200 & 1,60078 \\
Mode & 50,0000 & 72,5000 & 57,5000 & 70,0000 \\
Std. Deviation & 45,00 & 60,00 & $50,00^{\mathrm{a}}$ & 70,00 \\
Variance & 10,46297 & 9,92074 & 9,44513 & 7,15891 \\
Range & 109,474 & 98,421 & 89,211 & 51,250 \\
Minimum & 35,00 & 30,00 & 40,00 & 30,00 \\
Maximum & 40,00 & 60,00 & 30,00 & 50,00 \\
Sum & 75,00 & 90,00 & 70,00 & 80,00 \\
a. Multiple modes exist. The smallest value is shown \\
a.
\end{tabular}

\section{Hasil Analisis Deskriptif}

Hasil perhitungan analisis deskriptif dari tes awal dan tes akhir kelas eksperimen dan kelas kontrol menggunakan IBM SPSS Statistics 21. Berdasarkan hasil analisis tersebut diperoleh:

Berdasarkan tabel di atas diperoleh rata-rata hasil belajar matematika kelas eksperimen pada saat pre tes sebesar 54,00, median sebesar 50,00, modus sebesar 45, nilai maksimum sebesar 75 dan nilai minimum sebesar 40. Rata-rata hasil belajar matematika kelompok eksperimen setelah tindakan dengan strategi pembelajaran inkuiri yang dilengkapi pemberian tugas terstruktur sebesar 72,00, median 72,50, modus sebesar 60 , nilai maksimum sebesar 90 dan nilai minimum sebesar 60 .

Sedangkan rata-rata hasil belajar matematika kelas kontrol pada saat pre tes sebesar 55,50, median sebesar 57,00, modus sebesar 50, nilai maksimum sebesar 70 dan nilai minimum sebesar 30. Rata-rata hasil belajar matematika kelompok kontrol setelah tindakan dengan strategi pembelajaran ekspositori sebesar 67,25, median 70,00, modus sebesar 70 , nilai maksimum sebesar 80 dan nilai minimum sebesar 50 .

\section{Uji Normalitas Kelas Eksperimen dan Kelas Kontrol}

One-Sample Kolmogorov-Smirnov Test

\begin{tabular}{|c|c|c|c|}
\hline & & Progres Ekprimen & Progres Kontrol \\
\hline $\begin{array}{l}\mathrm{N} \\
\text { Normal Parameters } \\
\text { Most Extreme } \\
\text { Differences } \\
\text { Kolmogorov-Smirnov Z } \\
\text { Asymp. Sig. (2-tailed) }\end{array}$ & $\begin{array}{l}\text { Mean } \\
\text { Std. } \\
\text { Deviation } \\
\text { Absolute } \\
\text { Positive } \\
\text { Negative }\end{array}$ & $\begin{array}{r}20 \\
18,0000 \\
5,47723 \\
\\
, 208 \\
, 208 \\
-142 \\
, 930 \\
, 352\end{array}$ & $\begin{array}{r}20 \\
11,7500 \\
6,34014 \\
\\
, 259 \\
, 259 \\
-, 144 \\
1,157 \\
, 137\end{array}$ \\
\hline
\end{tabular}


Berdasarkan hasil output uji 0,137. Karena nilai signifikansi kedua kelas normalitas dengan menggunakan uji Kolmogorov-Smirnov, untuk kelas eksperimen nilai KSZ sebesar 0,930 dan Asym.sig. sebesar 0,352 dan kelas kontrol nilai KSZ 1,157 dan Asymp.sig. sebesar lebih besar dari $\frac{1}{2} \alpha(0,025)$ maka dapat disimpulkan bahwa data hasil belajar matematika kelas eksperimen dan kelas kontrol berdistribusi normal.

\section{Uji Homogenitas Varians dan Uji Hipotesis}

\begin{tabular}{|c|c|c|c|c|c|c|c|c|c|c|}
\hline \multicolumn{11}{|c|}{ Independent Samples Test } \\
\hline & & \multicolumn{2}{|c|}{$\begin{array}{c}\text { Levene's Test } \\
\text { for Equality of } \\
\text { Variances } \\
\end{array}$} & \multicolumn{7}{|c|}{ t-test for Equality of Means } \\
\hline & & \multirow[t]{2}{*}{$\mathrm{F}$} & \multirow[t]{2}{*}{ Sig. } & \multirow[t]{2}{*}{$\mathrm{t}$} & \multirow[t]{2}{*}{ Df } & \multirow[t]{2}{*}{$\begin{array}{l}\text { Sig. (2- } \\
\text { tailed) }\end{array}$} & \multirow[t]{2}{*}{$\begin{array}{c}\text { Mean } \\
\text { Difference }\end{array}$} & \multirow[t]{2}{*}{$\begin{array}{l}\text { Std. Error } \\
\text { Difference }\end{array}$} & \multicolumn{2}{|c|}{$\begin{array}{l}95 \% \text { Confidence } \\
\text { Interval of the } \\
\text { Difference }\end{array}$} \\
\hline & & & & & & & & & Lower & Upper \\
\hline \multirow{2}{*}{$\begin{array}{l}\text { Nilai } \\
\text { Progres }\end{array}$} & $\begin{array}{l}\text { Equal } \\
\text { variances } \\
\text { assumed }\end{array}$ &, 061 & ,807 & 3,336 & 38 &, 002 & 6,25000 & 1,87346 & 2,45737 & 10,04263 \\
\hline & $\begin{array}{l}\text { Equal } \\
\text { variances not } \\
\text { assumed }\end{array}$ & & & 3,336 & 37,215 &, 002 & 6,25000 & 1,87346 & 2,45474 & 10,04526 \\
\hline
\end{tabular}

Berdasarkan hasil analisis uji f nilai progress dengan menggunakan program IBM SPSS 21 diperoleh nilai $\mathrm{F}$ adalah 0,061 signifikan pada 0,807 lebih besar dari $\frac{1}{2} \alpha$ $(0,025)$, sehingga disimpulkan bahwa kedua kelas berasar dari varians yang homogen.

Sedangkan hasil uji-t diperoleh nilai $t_{\text {hitung }}$ 3,336 sig.(2-tailed) pada 0,002 lebih kecil dari $\frac{1}{2} \alpha(0,025)$ sehingga disimpulkan $\mathrm{H}_{0}$ ditolak dan $\mathrm{H}_{1}$ diterima. Hal ini berarti model pembelajaran inkuiri yang dilengkapi pemberian tugas terstruktur lebih efektif dibandingkan dengan model pembelajaran ekspositori.

\section{KESIMPULAN DAN SARAN}

\section{Kesimpulan}

Berdasarkan hasil pengolahan data dan pembahasan hasil penelitian maka dapat disimpulkan bahwa "Model pembelajaran inkuiri yang dilengkapi pemberian tugas terstruktur lebih efektif dari pada model pembelajaran ekspositori dalam meningkatkan hasil belajar matematika siswa kelas VIII SMP Negeri 2 Baubau”.

\section{Saran}

Berdasarkan hasil penelitian ini dapat disarankan beberapa hal sebagai berikut :
1. Diharapkan kepada guru mata pelajaran matematika agar dalam pelajaran menerapkan model pembelajaran inkuiri yang dilengkapi pemberian tugas terstruktur karena sangat efektif dalam meningkatkan hasil belajar matematika

2. Perlunya perbaikan/pembelajaran remedial bagi siswa yang belum tuntas belajarnya, dan perbaikan/ulang pada materi yang belum tuntas secara klasikal. 


\section{DAFTAR PUSTAKA}

[1] Adinawan, M. Cholik dan Sugijono. Matematika SMP Jilid 2B Kelas VIII Semester 2. Jakarta: Erlangga, 2004.

[2] Ambarwati, Leni. Keefektifan Metode Inkuiri dengan Pemberian Tugas Terstruktur dan Metode Inkuiri dengan Compact Disc (CD) terhadap Hasil Belajar Matematika dalam Materi Pokok Bangun Ruang Siswa Kelas VIII SMPN 30 Semarang. Skripsi Program Studi Pendidikan Matematika, Semarang: Perpustakaan Universitas Negeri Semarang, 2009.

[3] Arikunto, Suharsimi. Dasar-dasar Evaluasi Pendidikan. Jakarta: Rineka Cipta, 2002.

[4]

Penelitian. Jakarta: Rineka Cipta, 2002.

[5]

Penelitian. Jakarta: Rineka Cipta, 2006.

[6] Asyono. Matematika Kelas VIII SMP \& MTs. Jakarta: PT. Bumi Aksara, 2005.

[7] Bahri Djamarah, Syaiful. Strategi Belajar Mengajar. Jakarta: PT. Rineka Cipta, 2002.

[8] Dimyati dan Mudjiono. Belajar dan Pembelajaran. Jakarta: Rineka Cipta, 2002.

[9] Hardjoko, Mohamad. "Keefektifan Problem Posing dan Tugas Terstruktur pada Pembelajaran Mata Kuliah Pengantar Probabilitas pada Mahasiswa Semester 1 D3 Statistika
Terapan dan Komputasi Universitas Negeri Semarang Tahun Akademik 2002/2003". Skripsi. Universitas Negeri Semarang.

[10] Hartutik. Efektifitas Pembelajaran Biologi SMA dengan Pendekatan Jelajah Alam Sekitar (JAS) Berdasar Analisis SWOT dalam Kemasan CD Interaktif. Semarang: Tesis.

[11] Partanto, Pius A. dan Al-Barry, M. Dahlan. Kamus Ilmiah Popular. Surabaya: Arkola, 1994.

[12] Lisniawati Simanjuntak. Metode Mengajar Matematika 2. (Jakarta: Rineka Cipta, 1993).

[13] Mulyasa. Menjadi Guru Profesional Menciptakan Pembelajaran Efektif dan Menyenangkan. (Bandung: PT. Remaja Rosdakarya, 2007).

[14] Paul Suparno. Metodologi Pembelajaran Fisika Konstruktivistik dan Menyenangkan, (Yogyakarta: Universitas Sanata Dharma, 2007).

[15] Hamruni. Strategi Pembelajaran pada Siswa Semester Kelas VIII Semester 1 SMP NU 01 MUALLIMIN (2010 2011).

[16] Roestiyah Nk. Strategi Belajar Mengajar. (Jakarta: Rineka Cipta, 2008).

[17] Faridah. Efektivitas Model Pembelajaran Inquiry Discovery Learning, Terhadap Hasil Belajar Pendidikan Agama Islam. (Semarang: Jurusan Pendidikan Agama Islam IAIN, Walisongo, 2010). 